\title{
SEM of Ancient Jewelry
}

J. V. Taylor*, E. R. Wright*, A. Miller**, and R. Stein**

* Robert P. Apkarian Integrated Electron Microscopy Core, Emory University, 1515 Dickey

Drive, Atlanta, GA 30322

** Michael C. Carlos Museum, Emory University, 571 South Kilgo Circle, Atlanta, GA 30322

The purpose of this study was to examine ancient carved semi-precious stones and document the tool marks in order to determine how the carving was accomplished. This is an initial study and we wanted to see if tooling was evident when viewed in the Scanning Electron Microscope (SEM). It was hypothesized that SEM imaging would reveal clear cutting marks and suggest the tools used. We have evidence of tooling but we do not have the tools. Archeological evidence is lacking so we are examining the objects as a primary source and are reading them for their information. Four ancient Roman intaglio stones from the extensive collection held in the Carlos Museum were selected for this examination because they held some of the more striking faces. They include: Red Jasper Man one, Red Jasper Man two, Red Jasper Woman, and Carnelian Man, as referred to in the accompanying figures.

The faces carved into these stones were cut in negative relief and cut to a depth of more than a millimeter, particularly the nose in one case (Red Jasper Man two, detail of nose). Uniformly the backs of the stones are flat. These are carved cabochons of about 1 to 2 centimeters long and about 1 centimeter across. The stones are about 5 millimeters thick. Despite the fact these are all carved in negative relief, the images appear positive.

For the SEM study, the stones were secured to $1 \mathrm{~cm}$ diameter aluminum stubs using a small amount of carbon conductive tape, lightly applied to the under surface of the stones. It was necessary to easily release the stones from the stubs and to leave no residue of the adhesive. The carved stone samples, though stone, were not especially conductive and application of a conductive metal coating was not an option. Conductivity and charging were concerns so the imaging was performed at the low accelerating voltage of $5 \mathrm{kV}$.

The figures on the stones were imaged using a Topcon DS130 field emission scanning electron microscope (FESEM) at $5 \mathrm{kV}$ with magnifications ranging from $14 \mathrm{X}$ to $0.75 \mathrm{KX}$. Tool marks were very much in evidence when these stones were viewed in the SEM. The following figures are representative of this preliminary study. 

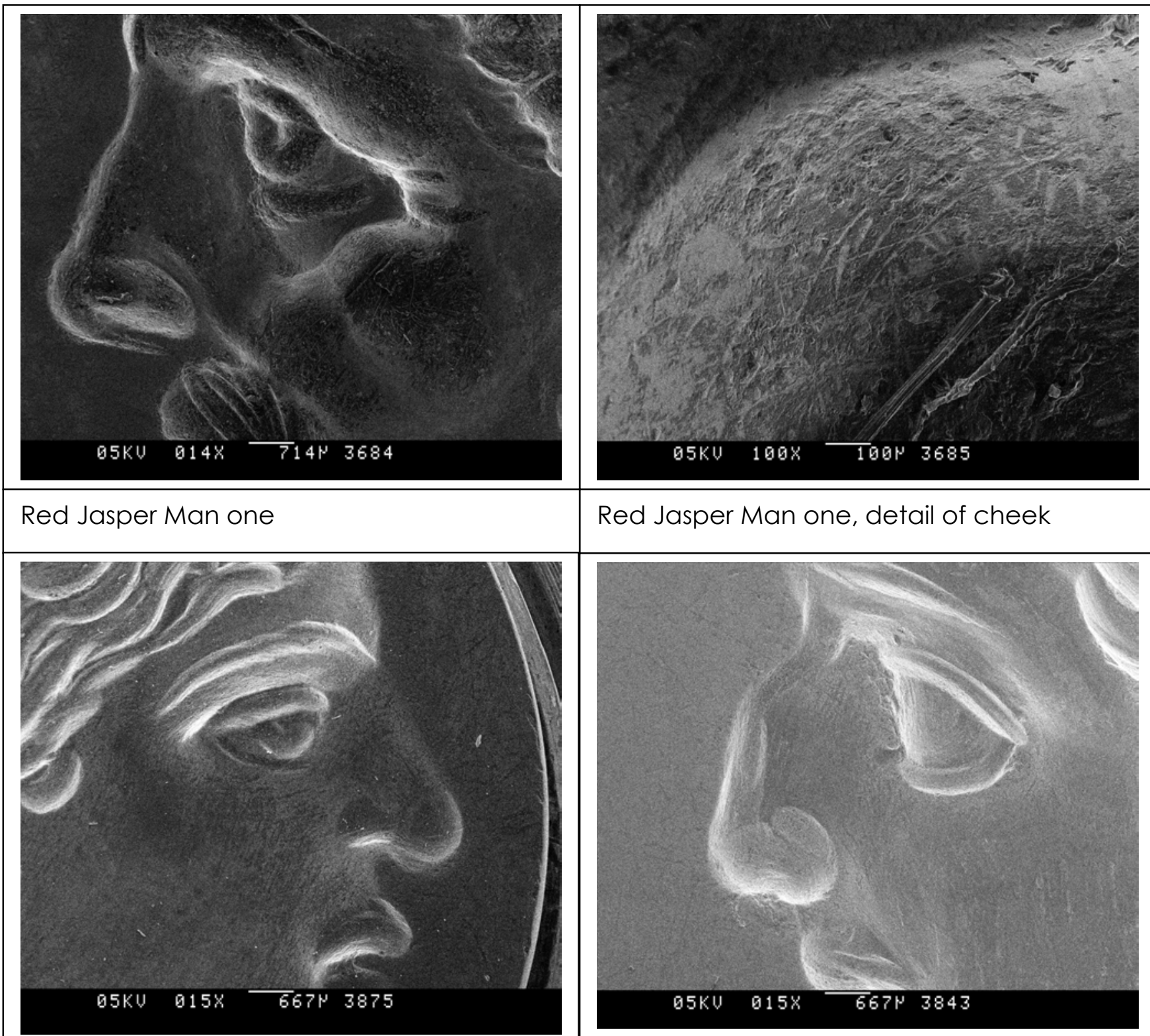

Red Jasper Man one, detail of cheek

\section{Red Jasper Woman}

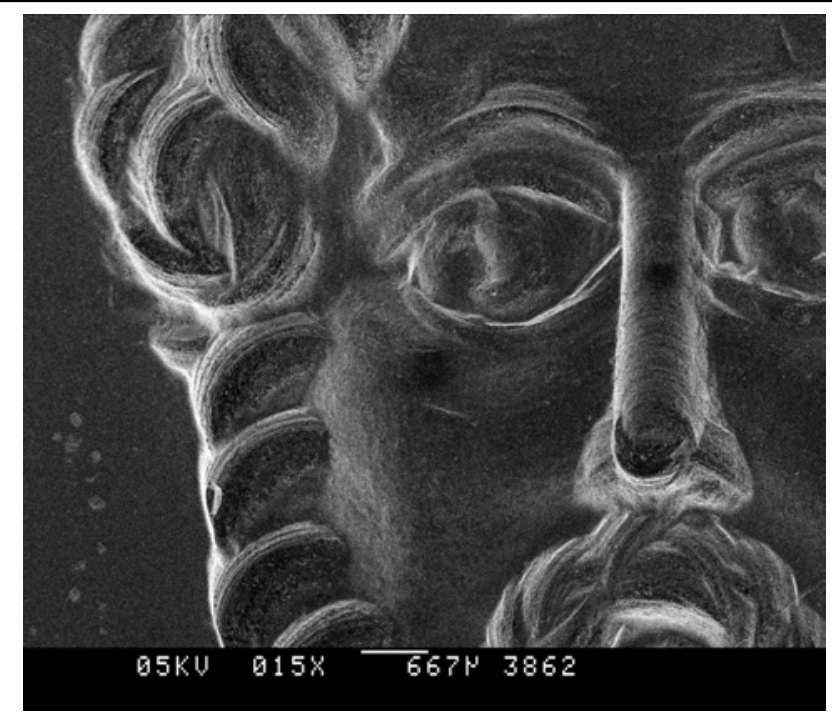

Red Jasper Man two

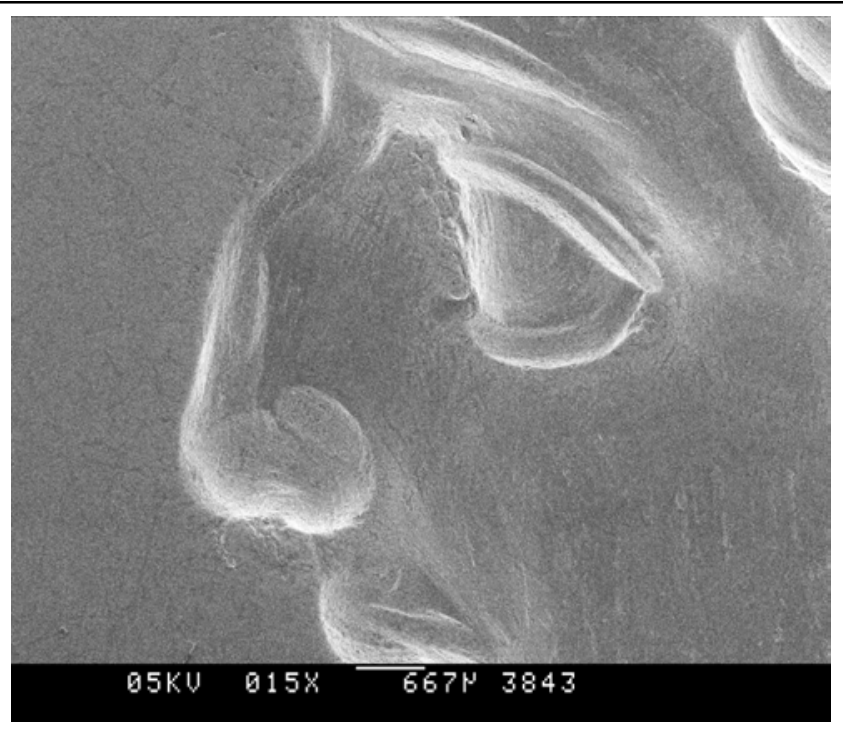

Carnelian Man

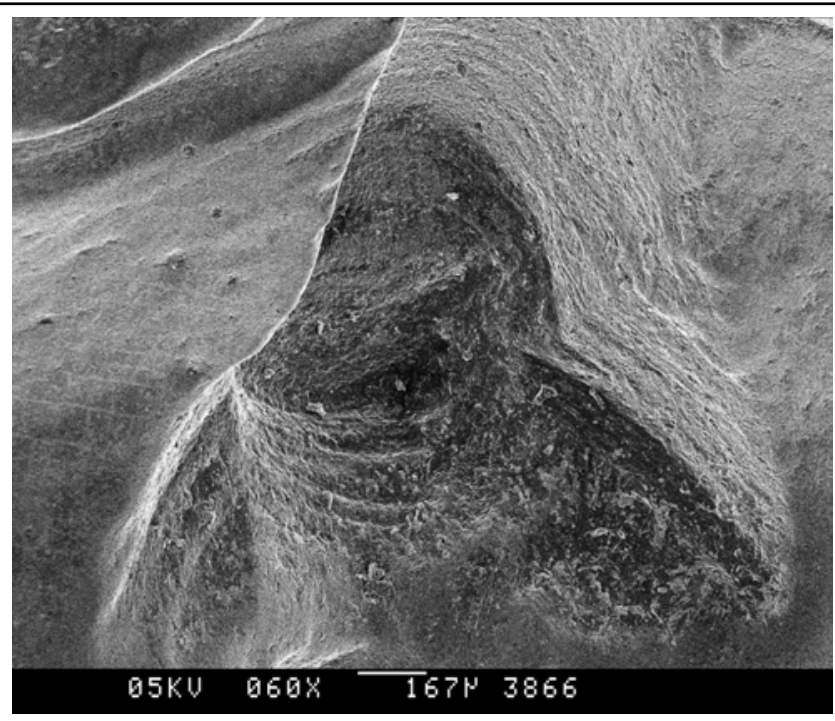

Red Jasper Man two, detail of nose 